\title{
O JOGO DE XADREZ COMO METODOLOGIA PARA O ENSI- NO DE GEOGRAFIA
}

\author{
THE GAME OF CHESS AS A METHODOLOGY FOR TEACHING OF GEOGRA- \\ $\mathrm{PHY}$
}

\section{EL JUEGO DEL AJEDREZ COMO UNA METODOLOGÍA PARA LA ENSEÑANZA DE LA GEOGRAFÍA}

\author{
Aparecida Pereira Soares \\ Licenciada em Geografia pela Universidade Estadual de Montes Claros-UNIMONTES. \\ Professora efetiva no município de Cônego Marinho-MG. \\ cidamalaquias2010@hotmail.com \\ Selma Pereira Soares \\ Licenciada em Geografia pela Universidade Estadual de Montes Claros-UNIMONTES. \\ sel_malopes@hotmail.com
}

\begin{abstract}
RESUMO: Atualmente confrontamos com vários embargos perante o sistema educacional brasileiro. Novas formas de ensino são mais que necessárias para que processo de ensino aprendizagem seja realizado de forma coerente às novas exigências do mundo atual. Discorrendo a respeito de tal afirmativa, uma boa sugestão, para que as aulas se tornem mais dinâmicas, instigantes é a utilização do xadrez nas aulas de Geografia. Nosso objetivo é mostrar que o jogo de xadrez pode ser considerado promotor de um desenvolvimento cognitivo do aluno, facilitando ao mesmo, o estímulo do raciocínio lógico, da concentração, do convívio interpessoal, e capaz de construir, nestes, um pensamento crítico e reflexivo, no que se refere à análise das categorias geográficas de lugar, espaço e território. Consistindo, portanto, em uma ferramenta impar no processo ensino-aprendizagem. Assim, com base em pesquisas bibliográficas e na experiência prática na Escola Estadual Américo Martins, localizada em Montes Claros/MG, percebe-se a amplitude compensatória dos resultados obtidos no espaço escolar, após intervenções e oficinas realizadas na mesma. É sem dúvida alguma, de grande importância projetos que visem e incentivem a construção de valores e que estimulem o desenvolvimento, em todas as esferas dos educando no ambiente escolar, pois o conhecimento construído no espaço escolar é para toda vida.
\end{abstract}

PALAVRAS-CHAVE: Xadrez. Geografia. Aluno.

ABSTRACT: Currently we have confronted with various embargoes against the Brazilian educational system. New forms of teaching are more than necessary for the teaching process learning is carried out in a manner consistent with the new demands of today's world. Talking about such affirmative, a good suggestion for the classes become more dynamic and thought-provoking is the use of chess in geography lessons. Our goal is to show that the game of chess can be considered a promoter of cognitive development of the student, facilitating at the same, the stimulus of logical reasoning, concentration, of interpersonal relations, and able to build a critical thinking and reflective, as regards the analysis of the geographical categories of place, space, territory and power. Consisting in a unique tool in the teaching-learning process. So based on bibliographic research and practical experience in the Escola Estadual Américo Martins, located in Montes Claros/MG, if realizes the compensatory magnitude of the results obtained in schools, after interventions and workshops on the same. It is undoubtedly of great importance to projects that encourage the construction of values and to stimulate the development, in all spheres of educating in the school environment, because the knowledge built in the school space is for life.

KEYWORDS: Chess. Geography. Student.

$\overline{\text { Artigo recebido em setembro de }} 2014$

Aprovado em novembro de 2014

Cad. Pes., São Luís, v. 21, n. 3, set./dez. 2014 
RESUMEN: Enfrenta actualmente los varios embargos contra el sistema educativo brasileño. Nuevas formas de enseñanza son más que necesario para que el proceso de enseñanza aprendizaje sea realizado de forma consistente con las nuevas exigencias del mundo actual. Hablando de tal afirmativa, una buena sugerencia para que las clases sean más dinámicas, estimulantes es el uso del ajedrez en lecciones de Geografía. Nuestro objetivo es mostrar que el juego del ajedrez se puede considerar un promotor del desarrollo cognitivo del estudiante, facilitando al mismo, el estímulo de razonamiento lógico, concentración, de las relaciones interpersonales y, poder construir estos, un pensamiento crítico y reflexivo, como considera la análisis de las categorías geográficas del lugar, espacio y territorio. Consiste, por lo tanto, en una herramienta única en el proceso de enseñanza-aprendizaje. Basada en la investigación bibliográfica y la experiencia práctica en la Escuela Estadual Américo Martins, ubicado en Montes Claros/MG, percibirse cuenta de la magnitud de los resultados obtenidos en las escuelas compensatorias, después de las intervenciones y talleres sobre el mismo. Es sin duda de gran importancia proyectos que alientan la construcción de valores y estimular el desarrollo, en todas las esferas de los estudiantes en el ambiente escolar, porque el conocimiento construido en el espacio de la escuela es para toda la vida.

PALABRAS CLAVE: Ajedrez. Geografía. Estudiante. 


\section{1 | INTRODUÇÃO}

O professor é um dos grandes responsáveis pelo processo formativo dos educandos e a escola visa proporcionar e colaborar para o desenvolvimento social e educativo, incentivando assim os alunos a buscarem conhecimentos que propiciem a reflexão de mundo e construção de ideias, ou seja, o senso crítico. Rompe-se então a concepção vertical de ensino, em que o professor é uma autoridade e os alunos são sujeitos passivos e ouvintes que devem apenas adquirir as informações e seguir modelos. A partir dessa relação, surgem dificuldades no que se refere ao desenvolvimento educativo e social do aluno que têm como consequência um desinteresse do mesmo pelo conteúdo.

Isso posto, podemos afirmar que o objetivo deste trabalho é mostrar a importância dos jogos para o processo ensino-aprendizagem, mostrar que, com a utilização de jogos na sala de aula, podemos abordar os conteúdos ou reforçá-los de uma forma menos cansativa e assim tornar as aulas mais agradáveis, demostrando que o uso pedagógico do jogo de xadrez é um promotor do desenvolvimento cognitivo do aluno, facilitando-lhe o estímulo do raciocínio lógico, da concentração, do convívio interpessoal, sendo, inclusive, capaz de construir neste um pensamento crítico e reflexivo, no que se refere à análise das categorias geográficas de lugar, espaço e território.

Cabe ressaltar que o temor pelas mudanças no processo ensino-aprendizagem esteja ligado à falta de recursos financeiros, má renumeração, se tem ou não domínio por essas novas tecnologias. Na verdade, recursos didáticos, como a utilização do jogo de xadrez em sala de aula, são simples e baratos, podendo até mesmo ser confeccionados com materiais recicláveis pelos próprios alunos, embora reconheçamos que este processo depende do interesse do docente por tal método.

Na Geografia, por exemplo, quando trabalhamos Geopolítica, o xadrez apresenta-se como um instrumento que pode levar à percepção das diversas estratégias espaciais, quando Linhares (2008) expõe que, ao analisar um conflito armado entre dois países, pode levar o educando a perceber o jogo geopolítico na região, onde os países medem força e lutam pelo poder estratégico na região. Nesse sentido, apontar como as peças do xadrez estão estrategicamente sendo mexidas pelos principais protagonistas, diretos ou indiretos, nessa disputa de interesses, é uma forma notável de associação entre o jogo de xadrez e a Geografia.

Assim, o presente estudo trata-se de uma pesquisa de caráter qualitativo, cujo enfoque não necessitou do emprego de estatística para a análise dos dados. É um estudo de uma situação em que está inserido um problema que, por sua vez, como tema central deste estudo, foi implementado na Escola Estadual Américo Martins, situado no bairro Jaraguá, Rua das Paineiras, $s / n^{\circ}$, na cidade de Montes Claros/MG. Ressaltamos que as atividades foram desenvolvidas com todas as turmas regularmente matriculadas na escola e representam para os alunos uma prática optativa, já que é realizada em horário diferente das aulas regulares.

\section{2 | $O$ LÚDICO NA GEOGRAFIA: a utilização do jogo de xadrez como recurso didático}

O jogo no espaço escolar é, muitas vezes, visto como atividade lúdica que acontece somente na hora do recreio e nos momentos livres. Existe no jogo, contudo, algo mais importante do que a simples diversão e interação. O jogo revela uma lógica da subjetividade, tão necessária à estruturação da personalidade humana quanto a lógica formal das estruturas cognitivas. No processo de ensino-aprendizagem, o jogo tem sempre dois desempenhos: um lúdico, no qual o aluno encontra a satisfação ao jogar, sentindo-se motivado e incentivado a buscar o saber; outro 
educativo, pois o jogo educa para a convivência social em um mundo que possui leis e regras que precisam ser conhecidas e internalizadas. Assim, podemos afirmar que o jogo proporciona ao aluno, no processo de ensino-aprendizagem, sentir-se desafiado, testar hipóteses, questionar-se e questionar o parceiro com o qual interage.

É de essencial importância que os professores transmitam aos seus alunos os objetivos de trabalhar com os jogos, como o jogo de xadrez, no ambiente escolar. A prática desenvolve habilidades, tendo como destaque: memória, concentração, planejamento e tomadas de decisões. Nesse sentido, esse jogo é considerado como um excelente suporte pedagógico, visto que se relaciona com diversas disciplinas. A proposta pedagógica de inserir o jogo de xadrez no processo de ensino-aprendizagem visa preparar o aluno para que seja capaz de tomar decisões em situações que exigem o raciocínio rápido, em busca de formar cidadãos íntegros através de uma atividade lúdica. Como destaca Bergamo (2009, p. 5),

[...] Sabemos que o lúdico influencia no desenvolvimento do indivíduo e na sua vida social. Brincando o indivíduo ultrapassa o que não está habituado a fazer e apreende melhor o conhecimento. Por meio da brincadeira, a criança envolve-se no jogo e sente necessidade de partilhar com o outro. Brincando e jogando, o jovem terá a oportunidade de desenvolver capacidades indispensáveis na sua futura atuação profissional, tais como: atenção, afetividade, concentração, tomada de decisões e outras habilidades psicomotoras.

O jogo de xadrez possui características importantes, as quais podem desenvolver capacidades em diversos níveis. A respeito do raciocínio lógico, no jogo de xadrez, o aluno passa a ter contato com diversos exercícios que lhe são propostos, nos quais ele deve buscar a melhor combinação dos lances a serem realizados, tendo a sua frente inúmeras possibilidades.

Com esta metodologia, o aluno desenvolve habilidades e hábitos necessários à tomada de decisões. Não basta, no entanto, o aluno saber solucionar o problema ou o exercício proposto, analisando apenas uma parte do tabuleiro. É de extrema importância que ele seja capaz de ver o tabuleiro como um todo, sabendo que as peças não devem ser vistas isoladamente, mas sim, que elas fazem parte de um contexto geral, em que uma depende da outra. Esta característica evidencia um aprimoramento da compreensão, na solução de problemas pela análise do contexto geral.

No ensino da Geografia, o uso das técnicas, principalmente as ligadas a um estilo mais lúdico, torna-se cada vez mais recorrente em sala de aula, pois fica cada vez mais certo que elas podem contribuir para a melhoria do ensino, como afirma Banhara (2008, p.15):

\footnotetext{
Através da aplicação da intervenção e pela análise da participação dos alunos e resultados obtidos na aprendizagem dos mesmos, conclui-se que a utilização da tecnologia apoiada por várias mídias sendo um recurso que os jovens convivem diariamente e que gostam muito, produzindo grandes resultados na educação, acompanhado as mudanças que ocorrem na sociedade.
}

O jogo é um instrumento rico, por isso, através de oportunidades e riscos, cada jogador precisa encontrar as possíveis soluções. Como um agente facilitador da aprendizagem, por se tratar de algo dinâmico, exige um grande cuidado no seu projeto e desempenho. As atividades lúdicas podem ser o melhor caminho de interação entre os professores e alunos e entre os próprios alunos, para gerar novas formas de desenvolvimento e de reconstrução de conhecimento. 
Os aspectos lúdicos e cognitivos presentes no jogo são importantes estratégias para o processo ensino-aprendizagem de conceitos abstratos e complexos, difíceis de serem absorvidos e compreendidos dentro da metodologia tradicional de quadro e giz, favorecendo a motivação, o raciocínio, a argumentação, a sociabilização e a interação entre os alunos e os professores. (VASCONCELOS et al., 2012, p. 2).

As técnicas lúdicas são recursos relevantes e uma alternativa para ampliar o interesse dos alunos pelas aulas de Geografia. Isso, principalmente, porque a memorização de conteúdo pelo aluno é extremamente desestimulante. Desta forma, a ludicidade surge como uma ferramenta importante para o bem-estar mental do educando, para o exercício da relação com o mundo, com as pessoas, com os objetos e, consequentemente, faz despertar o gosto pelo conteúdo escolar.

O lúdico, no processo ensino-aprendizagem, desperta nos alunos uma série de fatores positivos como, por exemplo: desenvolve a criatividade, a sociabilidade e as inteligências múltiplas; enriquece o relacionamento entre os alunos e reforça os conteúdos já aprendidos. O lúdico leva o aluno a aceitar, respeitar e aumentar a interação e integração entre os participantes. Além disso, proporciona a autoconfiança e a concentração dos educandos.

Vasconcelos et al. (2012, p. 1) destaca:

O lúdico simboliza um instrumento pedagógico que leva ao professor a condição de condutor, estimulador e avaliador da aprendizagem. Animar o processo de ensino-aprendizagem é dever e função que cabe aos docentes desempenhar e, portanto, precisam ser competentes, investigadores, nutrir certos conhecimentos de forma a desenvolverem atividades que sejam divertidas.

O lúdico é um instrumento indispensável à aprendizagem, porém deve-se observar sempre a importância do planejamento pelo professor, já que o jogo deve estar inserido em suas atividades como suporte pedagógico e não como passatempo.

Quando planejamos e adaptamos jogos à realidade, estimulamos nos alunos um desejo de compreender o mundo, especificamente, inserindo o contexto em que vivem. Nessa conjuntura, colocamos em questão o ensino de Geografia, através do lúdico, que se fez a partir do jogo de xadrez (Figuras 1 e 2).

Figura 1 - Confecção dos tabuleiros e peças do jogo

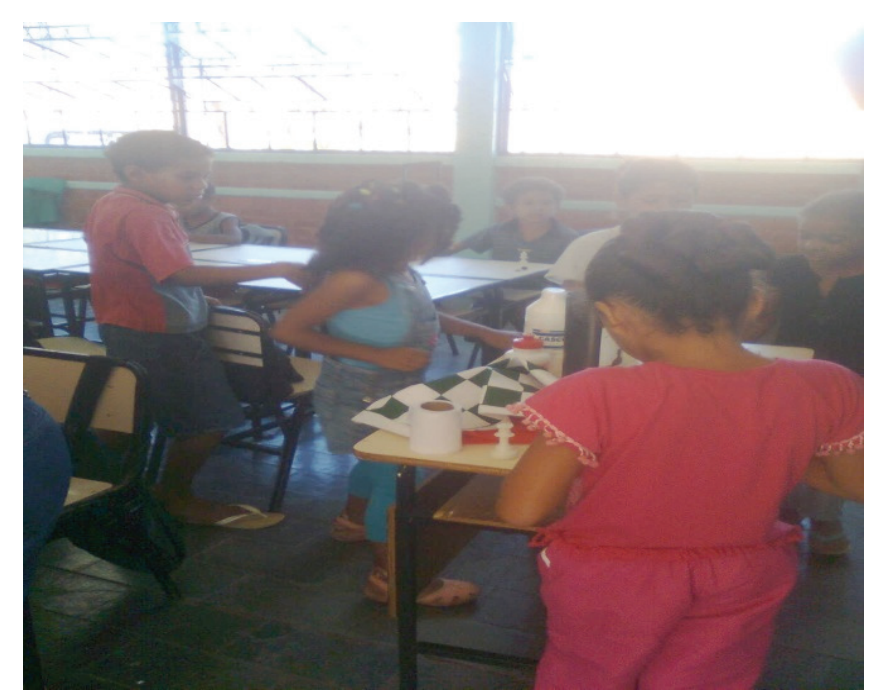

Fonte: Elaborado pelas autoras. 
Figura 2 - Explicação sobre a importância do xadrez na aprendizagem, para alunos do tempo integral, na Escola Estadual Américo Martins.

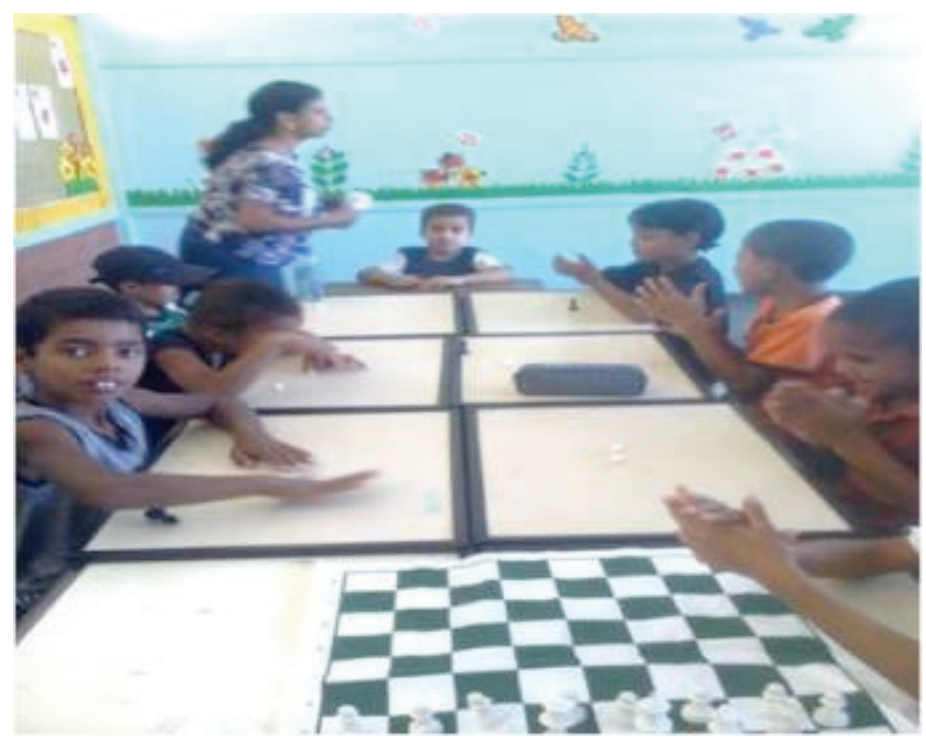

Fonte: Elaborado pelas autoras.

Na figura 1, podemos visualizar a distribuição dos participantes, com foco especial para a professora, com todos os participantes dispostos na mesa, para iniciar o jogo de xadrez.

Cabe ressaltar que o xadrez é, na Geografia, uma ferramenta facilitadora no processo de ensino-aprendizagem. Isto porque é uma atividade que não precisa de uma infraestrutura complexa, visto que é adaptável a qualquer lugar, o material é simples e tem uma vida útil extensa. É um jogo independente das novas tecnologias e de materiais onerosos, necessitando apenas de um simples tabuleiro e da teoria de um dos jogos mais antigos da espécie humana.

Como podemos notar, o xadrez é uma ampla ferramenta no aprendizado e não poderia ficar alheio ao processo ensino-aprendizagem de Geografia. Oliveira e Galvão (2013, p. 4-5) colocam que

O xadrez é, sem dúvidas, uma ferramenta didática facilitadora, pois não depende de novas tecnologias e materiais inovadores e caros, necessitam apenas de um pequeno tabuleiro, 32 peças e o ensinamento de um dos jogos mais antigos da humanidade. É uma atividade que não precisa de uma infraestrutura ampla (o xadrez é adaptável a qualquer ambiente em que estivermos), o material é simples e fácil de transportar, tem uma vida útil longa. Além do mais proporciona ao aluno uma melhor condição de raciocínio e consequentemente concentração, gerando, com isso, um avanço no nível escolar e apreensão dos temas escolares.

Dessa forma, por se tratar de uma ferramenta facilitadora, o emprego do jogo de xadrez é de grande relevância, pois ao se integrar essa metodologia nas escolas e instituições de ensino as mesmas serão pedagogicamente mais produtiva, visto que, é um importante instrumento pedagógico que ajuda no desenvolvimento da relação ensino-aprendizagem. 


\section{3 | ALIANDO O XADREZ À GEOGRAFIA: entendendo o território, o lugar, o espaço e o poder}

A Geografia fundamenta-se como uma ciência que estuda o espaço, relacionando-o de maneira a determinar a organização das pessoas. Como uma disciplina analítica, ela exige uma construção teórica que difere da tradicional decoreba. Assim, como nas regras do jogo de xadrez, para construirmos a análise, é necessário o desenvolvimento da compreensão dos problemas e das possibilidades existentes. Ao estudarmos as categorias de análise geográfica de espaço, território e lugar, podemos relacioná-las com o jogo de xadrez.

No que tange à categoria espacial, os alunos são levados a perceber e analisar um determinado espaço para melhor atuar sobre ele, no caso das jogadas, isto pode ser bem notado. No jogo de xadrez, colocamos o tabuleiro de forma que o ângulo direito inferior tenha uma casa branca, daí a noção da categoria espaço instigada nos alunos. Ainda, reforça-se esta categoria, ao evidenciar no jogo que todas as peças podem mover-se para frente ou para trás, com exceção dos peões que podem mover-se apenas para frente.

Nossa concepção de espaço surge, a partir da intencionalidade social, por meio da qual o homem se apropria do espaço natural, transformando-o, através do trabalho, em espaço geográfico, ou seja, é resultado e condição da dinamicidade de relações que os homens estabelecem cotidianamente entre si, com a natureza e consigo mesmo. Revela, ainda, contradições e desigualdades sociais:

\footnotetext{
Um conceito básico é que o espaço constitui uma realidade objetiva, um produto social em permanente processo de transformação. $O$ espaço impõe sua própria realidade, por isso a sociedade não pode operar fora dele. Consequentemente, para estudar o espaço, cumpre apreender sua relação com a sociedade, pois é esta que dita a compreensão dos efeitos dos processos (tempo e mudança) e especificam as noções de forma, função e estrutura, elementos fundamentais para a nossa compreensão da produção do espaço. (SANTOS, 2008, p. 67).
}

O conceito território vem sendo amplamente debatido, nas últimas décadas, existindo divergências entre pesquisadores sobre sua definição. Dessa forma, em relação ao território, podemos estabelecer a relação das peças do jogo do xadrez, nas casas do tabuleiro, com o estudo do território: cada peça tem o seu território delimitado pelo movimento de todas as peças. Assim, entendemos que o território se forma, a partir de uma relação espaço/tempo e, ao se apropriar de um espaço, em determinado tempo, a sociedade o territorializa.

A categoria território justaposta nas regras do xadrez apresenta-se como uma aprendizagem significativa, pois no jogo é claramente demonstrado que em cada casa pode haver apenas uma peça e, se um jogador deseja se apoderar de uma casa ocupada pelo adversário, poderá tomar a peça que ali estiver tirando-a do tabuleiro e colocando sua peça no lugar, o que remonta, também, à aprendizagem da categoria geográfica lugar.

Convém ressaltar que no jogo de xadrez não é obrigatório tomar-se peças. As peças tomadas saem do jogo. Os peões tomam as peças que estiverem nas casas diagonais logo à sua frente. $O$ rei é a única peça que pode tomar, mas não pode ser tomado. A compreensão dessa regra é fundamental: quando um rei está sendo ameaçado, é necessário que seja defendido. Se não houver defesa, o jogo termina. Diante do exposto, é fundamental que o aluno seja instigado na defesa de seu território, compreendido pelo espaço ocupado pelas peças.

Diante da premissa exposta, a utilização do território pelo homem cria o espaço, projetado pelo trabalho. Portanto, esse domínio exercido sobre um determinado espaço, a Geografia chama de 
Território, e todo espaço definido e delimitado a partir de relações de poder é um território.

Haesbaert (2004) afirma que podemos agrupar a concepção de território em três vertentes básicas: política referente às relações espaço-poder; cultural que prioriza a dimensão simbólica e mais subjetiva e econômica como fonte de recursos.

Santos (2005) compreende território sob a perspectiva do uso. Para o autor, o território usado constitui-se como um todo complexo onde se tece uma trama de relações complementares e conflitantes. Deve ser compreendido como uma totalidade que vai do global ao local. Em sua análise, o autor argumenta que o território em si não é um conceito, ele só se torna um conceito, quando o consideramos na perspectiva do seu uso. Tal entendimento é excessivamente importante, visto que tem como inquietação principal a ação e o uso desempenhado pelos seres humanos, na produção do espaço.

Há a necessidade de compreender o território concomitante à paisagem, ao espaço e ao lugar, entendendo-os não somente como um instrumento para conhecer a realidade, mas também como um excelente meio para conhecer o modo de observar a realidade e de usá-la. Isto porque não existe concepção dos processos na sua conjuntura, sem ajuda de uma imagem, especialmente, a partir das novas conformações territoriais materializadas no espaço (RAFFESTIN, 2010).

O conceito de território ganhou novas perspectivas, em virtude das possibilidades de abordagem estabelecidas sobre o tema por importantes estudiosos. $\mathrm{O}$ avanço sobre o entendimento de território vem contribuindo para a produção de pesquisas críticas e preocupadas com as relações estabelecidas, a partir do uso e apropriação, o que evidencia o caráter dinâmico do conceito e da própria geografia como ciência.

No que se refere à categoria geográfica de lugar, podemos notar que os diferentes espaços possuem distintas normas, regras e formas. Há essas peculiaridades nos espaços, as quais são chamadas de lugar. No jogo de xadrez, cada peça no tabuleiro tem seu lugar. Assim, o jogador não pode ficar encurralado e a conquista pela vitória é a conquista pelo poder.

O lugar é o espaço vivido, dotado de significados próprios e particulares que são transmitidos culturalmente. Nos estudos, a percepção do indivíduo, os símbolos, a religiosidade, os valores e as identidades coletivas são considerados.

Para Carlos (1997, p. 303),

[...] o lugar aparece como um fragmento do espaço onde se pode apreender o mundo moderno, uma vez que o mundial não abale o local. O lugar se produz na articulação contraditória entre o mundial que se anuncia e a especificidade histórica do particular. Deste modo, o lugar se apresenta como o ponto de articulação entre a mundialidade em constituição e o local enquanto especificidade concreta, enquanto momento.

Nesse sentido, o lugar é fruto da articulação estabelecida entre o mundial e o específico e particular. O lugar permitiria descobrir a sociedade atual, na medida em que aponta para a globalidade. Enquanto parcela do espaço, enquanto construção social, o lugar abre probabilidade para pensarmos o viver e o habitar, o uso e o consumo, os processos de apropriação do espaço. Ao mesmo tempo, posto que preenchido por múltiplas coações, o lugar expõe as pressões que se exercem em todos os níveis (CARLOS, 1997).

Feitas estas considerações, podemos afirmar que os educandos serão instigados a analisar a relação entre espaço, lugar, território e poder, aliados ao exercício do jogo do xadrez que os faz pensar, refletir e correlacionar a prática do jogo com os conceitos chave da geografia. 


\section{3 | ALIANDO O XADREZ À GEOGRAFIA: entendendo o território, o lugar, o espaço e o poder}

Através deste trabalho, foi possível entender a importância da utilização dos jogos, com ênfase no jogo de xadrez, no processo educativo, como instrumento facilitador da integração, da sociabilidade, do despertar lúdico e, principalmente, do aprendizado. Contudo, podemos enfocar a necessidade de alguns cuidados que devem ser tomados, ao levarmos um jogo para a sala de aula, ressaltando a importância de oferecer aos participantes as informações necessárias, para que a sua participação possa ser autoconsciente, esclarecida e livre, sendo, ainda, respeitados os valores culturais, sociais, morais e religiosos dos participantes e de toda comunidade escolar envolvida.

O tipo e a qualidade das informações construídas e os procedimentos utilizados pelo presente trabalho foram orientados por diálogo entre os indivíduos da comunidade escolar, como: alunos, pais ou responsáveis e professores, por exemplo. O trabalho passou por um comitê de ética, visto que seria necessária a disponibilização de imagens de crianças, a fim de que os resultados da pesquisa pudessem ser divulgados e socializados, beneficiando assim a sociedade como um todo.

O presente estudo foi implementado na Escola Estadual Américo Martins, em Montes Claros/ MG e pretendeu verificar se a prática do jogo contribui para a percepção da criança de formas diferenciadas de lazer, para que elas interajam com o conteúdo ensinado e a disciplina, transformando-as em agentes criadores do seu próprio conhecimento num processo dialético. Transformando, também, a sala de aula e o próprio ambiente escolar num lugar aprazível e atrativo, combatendo, assim, o desinteresse e tédio dos alunos, o poder disciplinador e repressivo imposto na relação professor-aluno, que gera comportamentos agressivos, desinteresse e até mesmo podendo gerar evasão escolar.

O Projeto Xadrez com Prazer na Geografia só foi possível ser concretizado com o apoio da $22^{a}$ Superintendência Regional de Ensino (SRE) de Montes Claros e dos funcionários da escola, ambos doando não só materiais como peças do xadrez, premiações para os vencedores da competição.

Para que os alunos pudessem se familiarizar com a atividade feita pelos docentes de Geografia, após a apresentação do jogo de tabuleiro de xadrez com suas respectivas peças, foi explicado aos alunos as regras, as estratégias, a função de cada peça e por fim o objetivo do jogo, sem mencionar a verdadeira problematização do trabalho ali inserido (Figuras 3 e 4).

Figura 3 - Explicação sobre a importância do xadrez na aprendizagem, para alunos do tempo integral, na Escola Estadual Américo Martins.

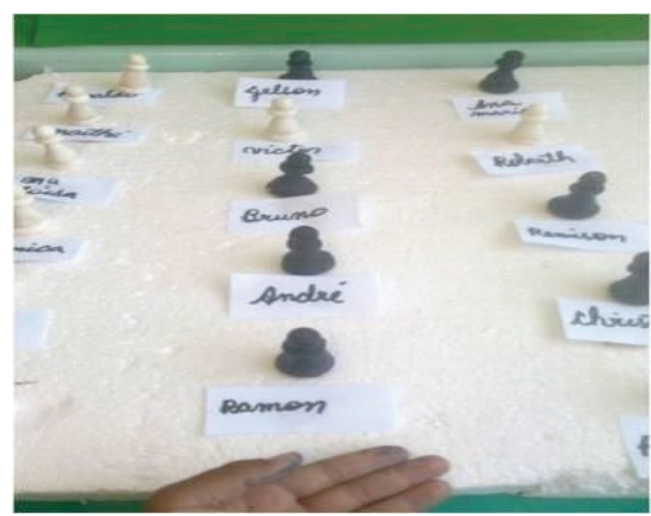

Fonte: Elaborado pelas autoras. 
Figura 4 - Alunos sendo organizados segundo regra do jogo a ser iniciado.

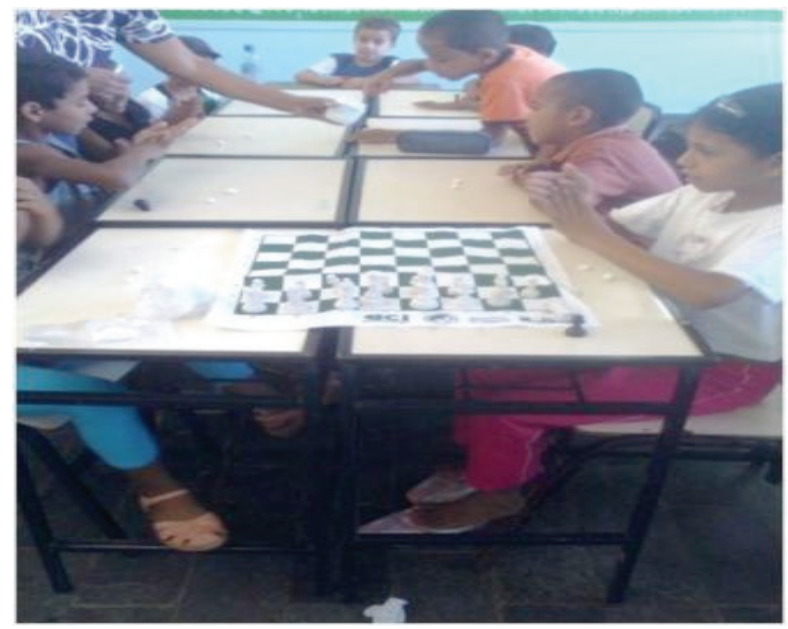

Fonte: Elaborado pelas autoras.

Podemos observar, na figura 3, que cada peça contém o nome de cada participante. Após o professor apresentar as peças do jogo, foram solicitados aos alunos que decidissem entre si e de comum acordo quem jogaria primeiro, incentivando-os a agirem com sentimento de solidariedade, cortesia e respeito aos colegas. Posteriormente, os alunos foram divididos em grupos de oito pessoas, como podemos visualizar na figura 4, iniciando as partidas com dois jogadores, seguido de rodízio com os demais. Para cada partida, foi estipulado tempo médio de 30 minutos, sendo utilizados os três primeiros horários de aula do dia, para a realização de tais atividades.

Ao exercitar os alunos com o xadrez, foram programadas competições entre eles, na Escola Estadual Américo Martins, sempre no término do ano e, para incentivá-los a participar, foram inseridas premiações em valores quânticos para os três primeiros vencedores. A quantidade de alunos praticantes de xadrez no evento oscila entre 80 a 100 alunos, já que depende da vontade de participação deles.

Ressaltamos, ainda, que as atividades com xadrez e a participação dos alunos no projeto não é obrigatória. Contudo, como foi observado por todos, discentes e docentes, o xadrez foi uma excelente forma de elevar a atenção e a concentração dos alunos, a imaginação, a memória, a vontade de vencer, a paciência, o autocontrole, o espírito de decisão, a coragem, a lógica, o raciocínio, a criatividade, a inteligência, a organização. Foram, portanto, diversos os benefícios levados à comunidade, tanto intelectual, quanto pessoalmente, o que contribui para que a participação a cada ano se torne cada vez mais intensa.

Após a realização do projeto, os alunos iniciaram sua participação em torneios de xadrez que acontecem semestralmente na escola, destacando-se, inclusive, recebendo premiações pelo mérito de colocação nos campeonatos.

$\mathrm{Na}$ escola, foi possível perceber que houve melhora no desempenho dos alunos, bem como uma maior integração entre eles. Também foi possível identificar que a experiência do diálogo entre as disciplinas contribui para o aumento da responsabilidade e do interesse dos alunos pelas aulas, assim como sua atuação como cidadãos, para além do espaço escolar. O projeto até hoje continua sendo realizado na escola, e o interesse e número de participantes é cada ano maior. 


\section{5 | CONSIDERAÇÕES FINAIS}

Podemos afirmar que o xadrez é um elemento promotor de um maior desenvolvimento cognitivo do sujeito aprendente, facilitando o processo ensino-aprendizagem. Além de uma prática de ensino diferenciada, o jogo de xadrez possibilita uma reflexão e concentração para os discentes, em suas diversas atividades cotidianas, mais explicitamente, as relacionadas à sala de aula, aumentando e estimulando um maior senso crítico e concentração dos alunos, tendo em vista que esse jogo estimula a capacidade de concentração do aluno e o instiga a ser mais participativo, no momento em que ele está participando ativamente do processo ensino-aprendizagem, de uma maneira diferente e divertida.

A proposta dentro da Geografia com o campeonato de xadrez é que os alunos compreendam as categorias geográficas, o que fez com que eles tivessem a noção de espaço, território e poder, na medida em que movimentavam as peças sobre a mesa e planejavam a melhor estratégia para arrematar o jogo.

Ressalta-se que essa metodologia com o jogo de xadrez pode ser usada por alunos de várias séries e é uma técnica bastante proveitosa, pois envolve os alunos fazendo com que eles se sintam motivados, além de ser uma forma diferente de se trabalhar o conteúdo das disciplinas. Como o lugar do conhecimento adquirido, a escola deve estar aberta a essas mudanças.

Para que o processo ensino-aprendizagem tenha eficácia, "é necessário partir da consciência da época em que vivemos, sabendo o que o mundo é e como ele se define e funciona. É somente assim que se podem formar cidadãos conscientes e capazes de atuar no presente, ajudando a construir o futuro" (SANTOS, 2008, p.115). E, sobretudo, através da dinamicidade do jogo de xadrez na Geografia, constituir sujeitos críticos capazes de compreender e atuar sobre as relações espaciais, nas mais diversas situações e criações das práticas e atividades humanas. 


\section{Referências}

BANHARA, G. D. A utilização de novas tecnologias no ensino de Geografia. Curitiba, 2008. Disponível em: <http://www.diaadiaeducacao.pr.gov.br/portals/pde/arquivos/2125-8.pdf>. Acesso em: 7 jan. 2014.

BERGAMO, M. O uso de metodologias diferenciadas em sala de aula: uma experiência no ensino superior. Londrina, 2009. Disponível em: <http://www.univar.edu.

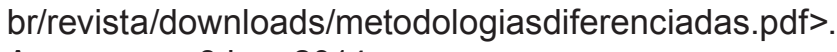
Acesso em: 8 jan. 2014.

CARLOS, A. F. A. O lugar: mundialização e fragmentação. In: SANTOS, M. et al. (Org.). O novo mapa do mundo: fim de século e globalização. São Paulo: Hucitec, 1997.

HAESBAERT, R. Des-caminhos e perspectivas do território. In: RIBAS, A. D.; SPOSITO, E. S.; SAQUET, M. A. Território e desenvolvimento: diferentes abordagens. Francisco Beltrão: Unioeste, 2004.

LINHARES, Maria Yedda. O oriente médio e o mundo árabe. SP, Brasiliense, 2008.
OLIVEIRA, K. de; GALVÃO, I. R. O xadrez como ferramenta para o ensino de Geografia: A experiência do PIBID na Escola Estadual Floriano Cavalcanti, em Natal/RN. In: ENCUENTRO DE GEÓGRAFOS DE AMÉRICA LATINA, 14., 2013, Lima. Anales... Lima: CGP, 2013.

RAFFESTIN, C. Uma concepção de território, territorialidade e paisagem. In: PEREIRA, S. R.; COSTA, B. P. da; SOUZA, E. B. C. de (Org.). Teorias e práticas territoriais: análises espaço-temporais. São Paulo: Expressão Popular, 2010.

SANTOS, M. O retorno do território. Debates: Territorio y movimientos sociales, Buenos Aires, ano VI, n. 16, enero/abr. 2005. USP, 2008.

Espaço e método. São Paulo: Editora da

VASCONCELOS, E. da S. et al. Jogos: uma forma lúdica de brincar. In: CONGRESSO NORTE NORDESTE DE PESQUISA E INOVAÇÃO, 7., 2012, Palmas. Anais... Palmas: IFTO, 2012. 